\title{
JANELA GEOGRÁFICA, UMA EXPERIÊNCIA EDUCOMUNICATIVA HOLÍSTICA NO ENSINO DE GEOGRAFIA
}

\section{Clesley Maria Tavares do Nascimento ${ }^{1}$}

Universidade Regional do Cariri

Anderson Felipe Santos Oliveira ${ }^{2}$

Universidade Federal de Goiás

Enviado em 30 jul. 2020 | Aceito em 11 mar. 2021

Resumo: O presente artigo foi concebido para discorrer sobre as reflexões geradas a partir do projeto de iniciação científica: Janela Geográfica, que foi realizado por professoras e estudantes da Universidade Regional do Cariri (URCA), tendo como objetivo geral desenvolver a autonomia e o senso crítico dos graduandos, através da produção de vídeos para utilizá-los como ferramentas didáticopedagógicas no processo de ensino-aprendizagem do saber geográfico, dentro e fora da universidade. A Educomunicação e o holismo foram os pilares teóricos norteadores do percurso metodológico dessa pesquisa-ação. O vídeo "Paisagem expressão de vivência" é um resultado imagético de uma discussão maior sobre trabalhar, no ensino da Geografia, a Educomunicação e o holismo. A construção coletiva deste gerou debates sobre a temática abordada e incitou reflexões sobre o fazer pedagógico, além de possibilitar o desenvolvimento de habilidades e competências referentes a linguagem audiovisual.

Palavras-chave: Vídeo. Ensino de Geografia. Educomunicação. Holismo.

\section{GEOGRAPHIC WINDOW, A HOLISTIC EDUCOMMUNICATIVE EXPERIENCE IN GEOGRAPHY TEACHING}

Abstract: This article was designed to discuss the reflections generated from the scientific initiation project: Geographic Window, which was carried out by teachers and students at the Universidade Regional do Cariri (URCA), with the general objective of developing the autonomy and critical sense of students, through the production of videos to use them as didactic-pedagogical tools in the teachinglearning process of geographic knowledge, inside and outside the university. Educommunication and holism were the theoretical pillars that guided the methodological path of this action research. The video "Landscape expression of experience" is an imaginary result of a larger discussion about working, in the teaching of Geography, Educommunication and holism. The collective construction of this generated debates on the theme addressed and prompted reflections on pedagogical practice, in addition to enabling the develo pment of skills and competences related to audiovisual language.

Keywords: Video. Geography teaching. Educommunication. Holism.

VENTANA GEOGRÁFICA, UNA EXPERIENCIA EDUCOMUNICATIVA HOLÍSTICA EN LA ENSEÑANZA DE LA GEOGRAFÍA Resumen: Este artículo fue diseñado para discutir las reflexiones generadas a partir del proyecto de iniciación científica: Ventana Geográfica, que fue realizado por docentes y estudiantes de la Universidade Regional de Cariri (URCA), con el objetivo general de desarrollar la autonomía y el sentido crítico de los estudiantes de pregrado, mediante la producción de videos para utilizarlos como herramientas didácticopedagógicas en el proceso de enseñanza-aprendizaje del conocimiento geográfico, dentro y fuera de la universidad. La educomunicación y el holismo fueron los pilares teóricos que guiaron el camino metodológico de esta investigación acción. El video "Paisaje expresión de la experiencia" es el resultado imaginario de una discusión más amplia sobre el trabajo, en la enseñanza de la Geografía, la Educomunicación y el holismo. La construcción colectiva de éste generó debates sobre el tema abordado y suscitó reflexiones sobre la práctica pedagógica, además de posibilitar el desarrollo de habilidades y competencias relacionadas con el lenguaje audiovisual.

Palabras clave: Video. Enseñanza de la geografía. Educomunicación. Holismo.

1. Professora Adjunta do Departamento de Geociências da Universidade Regional do Cariri - URCA, Doutora em Geografia pelo Programa de Pós-Graduação de Geografia - PROPGEO da Universidade Estadual do Ceará - UECE, ORCID: https://orcid.org/0000-0001-5531-0311.Email: clesleytavares@gmail.com.

2. Mestrando em Geografia pela Programa de Pós-Graduação em Geografia da Universidade Federal de Goiás - UFG, Graduado em Geografia pela Universidade Regional do Cariri- URCA. ORCID: https://orcid.org/0000-0002-8882-3495. Email: andersonfelipexiv@gmail.com. 


\section{Primeiras aproximações}

Apesar da ampla discussão referente ao caráter tradicional no ensino da Geografia, a construção do saber geográfico ainda se encontra, em grande medida, restrita à linguagem verbal e escrita em detrimento do uso de outras linguagens (audiovisual, SIG $^{3}$, teatral, plástica). A sensação que se tem é que a dinâmica da sala de aula acontece em uma realidade dissonante com aquela vivenciada na contemporaneidade, marcada pelo uso rotineiro de novas tecnologias e o acesso às redes sociais.

A comunicação entre esses dois mundos é imprescindível para que educadores(as) e educandos(as) se apropriem da força e vigor do saber geográfico. O espaço geográfico deve ser aprendido no interior da complexidade social e fazer uso de novas formas de expressão. Consequentemente, a missão e os instrumentos são outros e, principalmente, a linguagem é outra. (OLIVA, 2008)

A Geografia, enquanto ciência que estuda as relações que permeiam as transformações socioespaciais, tem o dever de discutir, de forma crítica, as alterações que o uso das novas tecnologias provocou na interação entre os lugares, nas relações sociais, econômicas e nos hábitos culturais. Diante da impossibilidade de evitar as novas demandas que se configuram no cotidiano, é imprescindível que professores e professoras se apropriem das atuais tecnologias e as convertam em instrumentos didáticos.

Conforme aumenta a veiculação de informações, ainda que de forma desigual, as tecnologias avançam para uma sociedade conectada por dispositivos cada vez mais portáteis. Atualmente, a chamada "era da informação" demonstra uma sociedade articulada a uma rede mundial de pessoas e informações constantemente atualizadas. Essas redes globais concatenadas chegam aos contextos educacionais na forma de novas ferramentas pedagógicas, a questão agora é aferir em que medida elas podem auxiliar ou atrapalhar o processo de ensino e aprendizagem dentro e fora de sala de aula.

Não se trata de criar mais uma das fantasias pedagógicas, comuns às burocracias normativas do ensino, frequentemente pensadas sem consulta basilar e alheia as dificuldades oriundas do sucateamento da educação, principalmente a pública. Entretanto, a factual rapidez com que o conhecimento é produzido e pulverizado nas redes de internet exige que se repense nossa relação com as ferramentas didáticas midiáticas, em particular com o audiovisual, construindo propostas que ofereçam experiências ricas e variadas de produção do saber geográfico (BARBOSA, 2008; SELBACH, 2010.).

Diante do exposto e conscientes dos desafios que envolvem a implementação de recursos tecnológicos na educação, propomos aqui fomentar o desenvolvimento da autonomia e criticidade dos(as) educandos(as) através da produção autoral de vídeos educativos que possam servir como ferramenta didático-pedagógica no processo de ensino-aprendizagem do saber geográfico dentro e fora da universidade, apresentando os proveitosos resultados de uma experiência realizada com alunos(as) do curso de Geografia da URCA. Nas palavras de Paulo Freire (2020), o ser humano ao

${ }_{3}$ SIG - Sistema de Informações Geográficas. 
acrescentar algo ao mundo do qual ele mesmo é criador vai temporalizando os espaços geográficos e dinamizando o mundo. À medida que ele cria, recria e decide, faz história.

O surgimento de plataformas de veiculação de vídeos (Youtube, Facebook, Vímeo, dentre outros) e o abastecimento diário dessas, fizeram do vídeo um recurso comum ao nosso dia-a-dia com uma imensa quantidade de temas e situações que promovem diferentes sensações na imensidão de seguidores em todo mundo. Desse modo, acreditamos ser essencial ocupar esse espaço com experiências que possam contribuir ao ensino da Geografia.

Criar, produzir, editar e difundir conteúdos audiovisuais está cada vez mais ao alcance de pessoas não especializadas, ávidas por expressarem suas ideias e visão do mundo. Com um simples celular, uma câmera fotográfica digital é possível captar imagens e sons, porém, não podemos esquecer o teor ideológico retratado. Uma vez que o alto volume de material audiovisual produzido nem sempre é consistente e acompanhado de reflexões críticas. (PAZZINI e ARAÚJO, 2013).

A partir dessa perspectiva, surgiu a ideia do projeto de produção de vídeos educativos Janela Geográfica, no intuito de enriquecer a formação de nossos discentes, desenvolvendo competências pedagógicas midiáticas, através da linguagem audiovisual, abordando temas que promovam o pensamento crítico sobre seu cotidiano e sua formação profissional.

$\mathrm{O}$ vídeo, frente às tecnologias que surgem como ferramentas que podem ser utilizadas no ensino, tem tido maior destaque nos últimos anos e nas instituições de ensino seu uso tem sido ressignificado. De acordo com Menezes (2017) a linguagem audiovisual traz para dentro da sala de aula o mundo externo, próximo e distante, as imagens e os sons do cotidiano, a imaginação e a fantasia. Deste modo, diversos sentidos são aguçados e a relação dos alunos com os conteúdos explanados se dá de maneira diferenciada.

Por outro lado, não podemos deixar de mencionar que tais transformações são acompanhadas com certo receio por muitos profissionais da educação, promovendo um descompasso entre a velocidade do uso de tecnologias digitais fora e dentro da sala de aula, onde, comumente, professores e professoras se sentem "ameaçados" de serem substituídos pelo volume de recursos didáticos surgidos da mediação de tecnologias com o ensino. Seria esse processo um indicativo do possível desmanche da civilização do livro e dos conteúdos sistematizados, entrando no mundo veloz, fluído e mutável da civilização audiovisual, caracterizada pela incerteza e a expectativa do novo, a cada minuto? (SOARES, 2000).

Acreditamos que uma coisa não desmancha a outra, pelo contrário agrega. Não são os livros ou os conteúdos sistematizados que são anacrônicos, mas sim a ideologia mercantilista da dualidade, que insiste em se contrapor a interconexão e integração das diversas formas de ver, ser e estar no mundo.

Sob o viés de tal complexidade, foi desenvolvido o projeto Janela Geográfica em conjunto com o grupo de pesquisa Educação Holística: um olhar integral na formação do docente de Geografia. 0 grupo tem a proposta de relacionar os saberes geográficos com os princípios da educação holística, o que inclui a interdisciplinaridade e o desenvolvimento humano integral, e não apenas preparar nossos alunos e alunas para o mercado de trabalho. Compactuamos com a ideia de Yus (2002) quando este afirma que o desenvolvimento humano deve preceder o desenvolvimento econômico, pois o ser humano é maior do que seus papéis de trabalhador e cidadão.

O projeto Janela Geográfica utilizou-se da linguagem educativa midiática constituída por elementos que unem a educação, inovação, estética e criatividade no seu processo de criação. A 
relação teórico-metodológica toma como base o campo da Educomunicação, termo surgido na década de 1990 a partir das discussões sobre educação e comunicação pelo Núcleo de Comunicação e Educação da USP.

O termo Educomunicação, no Brasil, é recente, data de 1999, cunhado pelo Prof. Dr. Ismar de Oliveira Soares, Professor e Pesquisador do Núcleo de Comunicação e Educação da Universidade de São Paulo (NCE/USP), pioneiro na identificação de um campo específico presente, especialmente, em iniciativas da sociedade civil organizada voltadas para a formação humana, sobretudo de crianças, adolescentes e jovens (HASLINGER, SAGGIN e ALBUQUERQUE, 2017, p.90)

Partindo da perspectiva educomunicativa, o projeto Janela Geográfica buscou construir uma proposta pedagógica imagética que contemplasse temas geográficos, produzindo vídeos coletivamente. Um dos intuitos foi gerar reflexões dialógicas pautadas na incerteza de que está sendo exposto, abertas a aceitação e a recusa, a divergência e a convergência. Enfim um diálogo que reflita os meandros da interação social.

\section{Educomunicação e educação holística no ensino da geografia}

Os debates que se iniciaram no final do século XX e início desse século, acerca da chegada das tecnologias na educação, mostram múltiplas experiências que contribuem na concepção assertiva dos diálogos levantados por diferentes autores. Essas experiências que se replicam em todo o território nacional fazem das linguagens contemporâneas, formas de projeção de novos paradigmas no ensino.

Entretanto, cabe destacar que, em uma sociedade como a nossa cada vez mais tecnológica/digital, é imprescindível à educação estabelecer uma relação dialética e contextualizada com a realidade a qual se destina. Ou seja, se por um lado os profissionais da área devem se capacitar para acompanhar a tecnologização da educação, por outro lado, não podem negligenciar a criticidade necessária à análise de sua condição sociocultural.

\footnotetext{
Os processos engendrados pelas atualizações tecnológicas comunicacionais, sobretudo digitais, integram (re)configurações que compreendem não apenas aspectos técnicos, mas contextos sociais e culturais que estruturam as formações discursivas dos sujeitos. Algumas dessas mudanças repercutem nas maneiras de interação, de acesso à informação, de produção, recepção e circulação de conteúdos, estendendo-se as formas de construção do sujeito e de relação com o outro, com os aparatos técnicos. Condições que solicitam outro olhar sobre os processos comunicacionais e suas interferências na dinâmica sociocultural, simbólica. (CORTES, MARTINS e SOUZA, 2018, p.2)
}

Esses apontamentos, para além das potencialidades exploradas pela inserção desses novos campos, têm sua observância maior nas sociedades através de suas relações cotidianas, mas haverá sua contra partida na educação se existir uma interferência na sociedade, assim os currículos oficiais nacionais também dão atenção para esses novos paradigmas do ensino diante das novas mídias. Essas determinações são observadas nos últimos projetos curriculares nacionais, tanto nos Parâmetros Curriculares Nacionais (PCNs. 1998) que estiveram em vigência nos últimos 20 anos, como também no novo currículo proposto na atual Base Nacional Comum Curricular (BNCC, 2018). 
Nos Parâmetros Curriculares Nacionais apesar de terem sido formulados na década 1990 do século anterior a este, no seu texto de apresentação mencionam sobre as novas habilidades e materiais que se fariam (e/ou deveriam) presentes na escola a partir das novas mídias da educação, e ainda reforçam a impossibilidade de ignorá-las.

É indiscutível a necessidade crescente do uso de computadores pelos alunos como instrumento de aprendizagem escolar, para que possam estar atualizados em relação às novas tecnologias da informação e se instrumentalizarem para as demandas sociais presentes e futuras. A menção ao uso de computadores, dentro de um amplo leque de materiais, pode parecer descabida perante as reais condições das escolas, pois muitas não têm sequer giz para trabalhar. Sem dúvida essa é uma preocupação que exige posicionamento e investimento em alternativas criativas para que as metas sejam atingidas (BRASIL, 1998, p.68).

Se posicionando quanto ao uso de tecnologia nas escolas, a BNCC aponta nas competências gerais a serem desenvolvidas na educação básica:

Compreender, utilizar e criar tecnologias digitais de informação e comunicação de forma crítica, significativa, reflexiva e ética nas diversas práticas sociais (incluindo as escolares) para se comunicar, acessar e disseminar informações, produzir conhecimentos, resolver problemas e exercer protagonismo e autoria na vida pessoal e coletiva. (BRASIL, 2018, p. 9)

Embora cientes que o acesso a computadores e à internet seja, muitas vezes, limitado para as pessoas de baixa renda, as discussões a respeito do uso dessas tecnologias são recorrentes em documentos norteadores da educação do país, haja vista que as reconhecem como ferramenta essencial para a interação entre o sujeito com o mundo pós-moderno, condição sine qua non na construção de qualquer conhecimento, seja ele formal ou não. Sendo assim, as mídias se inserem no conjunto de ferramentas da educação, como um recurso a mais para a prática docente em consonância com outros materiais impressos que compõem o arcabouço técnico docente.

Diante do exposto, cabe mencionar algumas questões não contempladas nas citações trazidas. O caráter virtual e sistêmico das novas tecnologias, dependendo como utilizadas, oportunizam o desengessamento dos currículos, pois possui a capacidade de transpor o "controle" do espaço escolar e a rigidez dos conteúdos disciplinares que frequentemente funcionam como base curricular. Em outras palavras, o acesso à informação e à circulação de conteúdos existentes nas redes sociais permite aos educandos entrar em contato com assuntos, discussões e reflexões sobre temas do seu interesse (gênero, racismo, masculinidade tóxica, religião, drogas, dentre outros) que muitas vezes não fazem parte dos currículos escolares, isso quando não são proibidos ou tratados de maneira preconceituosa.

Em grande medida, dentro do ambiente escolar, os estudantes são quem dominam o manejo dos aparatos tecnológicos, podendo assim protagonizarem a confecção de materiais didáticos de linguagem audiovisual, que reflitam suas experiências e interesses de aprendizagem. Deste modo, é necessário considerar que:

[...] as tecnologias vêm facilitar esse trabalho, porque trazem instrumentos e recursos que possibilitam a criação de redes, as chamadas redes sociais que podem se transformar em redes educomunicativas. Educar é da natureza da comunicação, enquanto você se comunica você está se educando e multiplicando esse trabalho. (RADDATZ, 2015, p.32) 
De fato, não há educação sem comunicação, embora seja possível comunicar sem educar, porém toda comunicação requer uma linguagem. Isso nos alerta para dois aspectos que não podem ser perdidos de vista no momento da elaboração de um material educativo, que são: o conteúdo/conhecimento e a linguagem. Vale destacar que consideramos linguagem como condição reflexiva de estar e ser no mundo, "[...] não podemos deixar de notar que os seres humanos somos humanos na linguagem, e ao sê-lo, o somos fazendo reflexões sobre o que nos acontece." (MATURANA, 2005, p.37)

[...] para a educomunicação, a comunicação é vista como um direito fundamental. E, diante disso, é importante que os estudantes possam se apoderar das linguagens midiáticas, ao fazer uso coletivo e solidário dos recursos da comunicação tanto para aprofundar seus conhecimentos quanto para desenhar estratégias de transformação das condições de vida à sua volta. A participação no processo de produção da comunicação traz resultados também na ampliação da cidadania dos sujeitos envolvidos. Isso ocorre porque o processo de elaboração dessa comunicação é educativo, não somente pelos conteúdos, mas pelo envolvimento direto das pessoas no fazer comunicacional. (PRÓSPERO, 2017, p. 66)

Participar da elaboração de um material de comunicação exige presença dos sujeitos envolvidos. Quem comunica ou dialoga com alguém sobre algo existente no espaço vivido requer uma atitude crítica e única, que não pode ser outorgada a outrem. Ao participar do processo de construção do seu conhecimento, o sujeito não apenas cria, mas também ressignifica os conteúdos que lhe são apresentados, integrando-os a sua forma de agir na cotidianidade.

Sob a ótica do cotidiano, estamos frequentemente buscando materializar grande parte do que aprendemos na escola, universidade e na vida, na tentativa de dar significado aos acontecimentos corriqueiros, que ocasionam transformações espaço-existenciais reveladores e amiúde indeléveis, "[...] que se efetivam em diversas linguagens, [...] geradora de conhecimentos e saberes sobre 0 espaço geográfico." (OLIVEIRA JUNIOR e GIRARDI, 2015, p. 4)

Desse processo, extraímos a ideia da produção do conhecimento a partir do que vivenciamos, buscando transpor, sistematizar, ressignificar e comunicar o que foi aprendido acerca de algo. A interpretação das particularidades do conhecimento formal, com a inserção das mídias no processo educativo, caminha em meio as novas experiências do mundo globalizado, onde o dinamismo de informações propicia um interesse maior dos alunos em aprender os conteúdos que the são apresentados, e aproveitar essa paleta multicolor de recursos.

A questão a ser considerada nesse processo é a ampla democratização desses recursos como anteriormente destacamos, por isso o projeto que apresentamos tenta contribuir com a maior circulação de materiais didáticos produzidos por alunos para uma experiência de ensino educomunicativo e holístico.

A Educomunicação e a Educação Holística são ramificações de práticas educacionais que vem sendo discutidas cada vez mais nos primeiros decênios do século XXI. Refletir sobre elas e suas interfaces com um olhar direcionado ao ensino da Geografia é uma tarefa minimamente curiosa e desafiadora, uma vez que nos oportuniza participar da construção de novos paradigmas da educação (Quadro 1).

Quadro 1 - Quadro Comparativo da Educação Tradicional, Educomunicação e Educação Holística 


\begin{tabular}{|c|c|c|c|}
\hline \multirow[b]{2}{*}{ INDICADOR } & \multicolumn{3}{|c|}{ PARADIGMA } \\
\hline & Educação Tradicional & Educomunicação & Educação Holística \\
\hline $\begin{array}{c}\text { Valores } \\
\text { predominantes }\end{array}$ & $\begin{array}{l}\text { Hierarquia, } \\
\text { autoritarismo, } \\
\text { competitividade, } \\
\text { individualismo }\end{array}$ & $\begin{array}{l}\text { Criatividade, } \\
\text { participação, } \\
\text { responsabilidade } \\
\text { social e ambiental, } \\
\text { coletivismo }\end{array}$ & $\begin{array}{l}\text { Integradora, } \\
\text { cooperação, } \\
\text { Inclusão, conexão, } \\
\text { criatividade, } \\
\text { espiritualidade }\end{array}$ \\
\hline Currículo & Rígido, prescritivo & Flexível, aberto & Aberto, global \\
\hline Objetivo/ meta & Resultado & Processo & Processo \\
\hline Visão de mundo & Mecanicista, linear & Global & Sistêmica, integral \\
\hline Comunicação & Monólogo & Diálogo & Diálogo \\
\hline $\begin{array}{l}\text { Veículos de } \\
\text { comunicação }\end{array}$ & Não disponibiliza & $\begin{array}{l}\text { Disponibiliza, gerida } \\
\text { por alunos/as }\end{array}$ & $\begin{array}{l}\text { Disponibiliza, gerida } \\
\text { por alunos/as }\end{array}$ \\
\hline Estimula & $\begin{array}{l}\text { Heteronomia, } \\
\text { obediência }\end{array}$ & $\begin{array}{l}\text { Autonomia, } \\
\text { criatividade }\end{array}$ & $\begin{array}{l}\text { Autonomia, } \\
\text { criatividade }\end{array}$ \\
\hline Gestão & Centralizadora & $\begin{array}{l}\text { Participativa, } \\
\text { transparente }\end{array}$ & $\begin{array}{l}\text { Participativa, } \\
\text { transparente }\end{array}$ \\
\hline Processo educativo & $\begin{array}{l}\text { Unilateral, transmissivo, } \\
\text { disciplinar }\end{array}$ & $\begin{array}{l}\text { Integral, dialógico, } \\
\text { inter e } \\
\text { transdisciplinar }\end{array}$ & $\begin{array}{l}\text { Integral, dialógico, } \\
\text { inter e } \\
\text { transdisciplinar }\end{array}$ \\
\hline Tarefas & $\begin{array}{l}\text { Competitivas, } \\
\text { direcionadas, } \\
\text { individuais }\end{array}$ & $\begin{array}{l}\text { Coletivas, } \\
\text { cooperativas e } \\
\text { interdependentes }\end{array}$ & $\begin{array}{l}\text { Cooperativas, } \\
\text { criativas e artísticas }\end{array}$ \\
\hline Estilo de liderança & $\begin{array}{l}\text { Autoritária e } \\
\text { centralizador }\end{array}$ & $\begin{array}{l}\text { Democrática e } \\
\text { descentralizadora }\end{array}$ & Empática \\
\hline Gestão de afetos & Distante e neutra & $\begin{array}{l}\text { Confiança, estimula } \\
\text { laços afetivos } \\
\text { profundos }\end{array}$ & $\begin{array}{l}\text { Acolhedora, } \\
\text { estimula laços } \\
\text { afetivos profundos }\end{array}$ \\
\hline $\begin{array}{l}\text { Novas tecnologias e } \\
\text { redes sociais }\end{array}$ & Pouco utilizadas & Utiliza bastante & $\begin{array}{l}\text { Utiliza com } \\
\text { frequência }\end{array}$ \\
\hline Avaliação & $\begin{array}{l}\text { Quantitativa, } \\
\text { classificatória }\end{array}$ & $\begin{array}{l}\text { Coletiva e } \\
\text { autoavaliação }\end{array}$ & $\begin{array}{l}\text { Autoavaliação e } \\
\text { formativa }\end{array}$ \\
\hline
\end{tabular}

Fonte: Elaborado pelo autor (2020) a partir de Ortiz (2017)

O Quadro 1 nos permite visualizar vários aspectos de interseção e similaridade entre a Educomunicação e a educação holística, perpassando pelos valores basilares da criatividade, cooperação, participação, dentre outros; um currículo aberto; objetivo da aprendizagem pautado no processo em detrimento do resultado (educação tradicional); visão de mundo não cartesiana; utilização das novas tecnologias como apoio didático e a autoavaliação como instrumento avaliativo são apenas alguns dos aspectos em comum.

Cabe aqui colocar que são ínfimas, se não inexistentes, pesquisas que contemplam a tríade: ensino da Geografia, Educomunicação e educação holística. Diante desse fato, o presente estudo não só contribui para discutir a relação da Educomunicação e as mídias no mundo da informação como também pode ajudar a esclarecer as implicações que estas vertentes educativas trazem ao ensino da Geografia. Didaticamente, "[...] implicam mudaças na postura, na linguagem e nas atividades de aprendizagem necessárias para que o aluno reflita sobre a realidade, a sociedade e a dinâmica do espaço." (CASTELLAR, 2005, p. 211), estimula a autonomia e a critividade dos sujeitos envolvidos, através da participação no processo de construção do conhecimento, sendo o prório sujeito a referência de percepção e análise da realidade. Diferentemente do ensino tradicional, onde a ênfase é no conhecimento enciclopédico, insípido e sem criatividade.

A Geografia, ciência que trata das interrelações espaciais, perante a complexidade do espaço globalizado, vê crescer a demanda por materiais didáticos que possam expressar e comunicar tal realidade. De acordo com Rodrigues e Manaia, atualmente processamos e consumimos informações a todo instante, porém devemos lembrar que informação não é conhecimento, pois este requer 
interpretação daquilo que está sendo informado, possibilitando assim a reelaboração de conceitos e o contexto no qual está inserido.

São em plataformas como Youtube e Vímeo, onde se encontram a maior parte de materiais audiovisuais que tentam abordar temas da ciência geográfica e ensiná-los. Com uma maior divulgação e circulação de materiais nessas redes, professores e pesquisadores têm produzido cada vez mais conteúdo para essas plataformas. Como exemplo temos: canais de cursos de pósgraduação, cursos de graduação, associações e entidades de Geografia que transmitem palestras e vídeos curtos sobre conceitos e temas da ciência, além dos canais de revisão para provas de vestibulares e concursos.

Portanto já está em curso um movimento de compartilhamento das mídias de maiores seguidores, alternativas complementares ao ensino da Geografia, e também de outras ciências. Em meio a esses trabalhos construir propostas educativas substanciais que possam ampliar esse debate se torna um ponto em comum importante, que pode contribuir nos espaços de formação e de divulgação cientifica.

\section{Pondo as palavras para andar}

O processo metodológico adotado seguiu uma abordagem qualitativa através da pesquisaação. Uma vez que agrega várias técnicas, utiliza-se de coleta e interpretação dos dados, de intervenção na solução de problemas e organização de ações, bem como de técnicas e dinâmicas de grupo para trabalhar com a dimensão coletiva e interativa na produção do conhecimento e programação da ação coletiva. (BALDISSERA, 2001)

Quanto ao procedimento metodológico propriamente dito, este foi dividido em sete etapas, referentes a articulação entre a fundamentação teórica, pesquisas do grupo e as filmagens do vídeo.

Etapa I - Consistiu-se na abordagem conceitual do projeto, onde se estabelece as diretrizes que seriam trabalhadas. Este momento proporcionou aos participantes uma visão geral das perspectivas teóricas do projeto.

A apresentação da proposta se deu através do grupo de pesquisa em Educação Holística do Departamento de Geociências da URCA, onde estudantes e professoras, integrantes do grupo, discutiram o desenvolvimento do projeto Janela Geográfica norteado pelos princípios da Educação Holística e a Educomunicação.

Etapa II - Contextualização e discussão referente aos principais conceitos geográficos e escolha de um deles para ser o tema do vídeo. O exercício buscou inicialmente problematizar às categorias e suas definições, entre diferentes autores e correntes da ciência geográfica. Visando evidenciar o leque de possibilidades que as categorias poderiam ser retratadas. A categoria Paisagem foi escolhida em detrimento dos conceitos de espaço, região, território e lugar.

Etapa III - Debate baseado na apresentação dos vários conceitos de paisagem, trazidos pelo grupo a partir de uma pesquisa bibliográfica individual (figura 01). Os conceitos seriam fundamenta is para abordagem do vídeo por meio de alguns teóricos do pensamento geográfico, assim poderíamos representar diferentes conceituações nas cenas capturadas e na narração durante o vídeo acerca da Paisagem, por isso, essa etapa teve fundamental importância, por influenciar diretamente na mensagem/conteúdo do vídeo. 
Figura 01 - Reuniões do Grupo para apresentação e discussão dos conceitos de paisagem

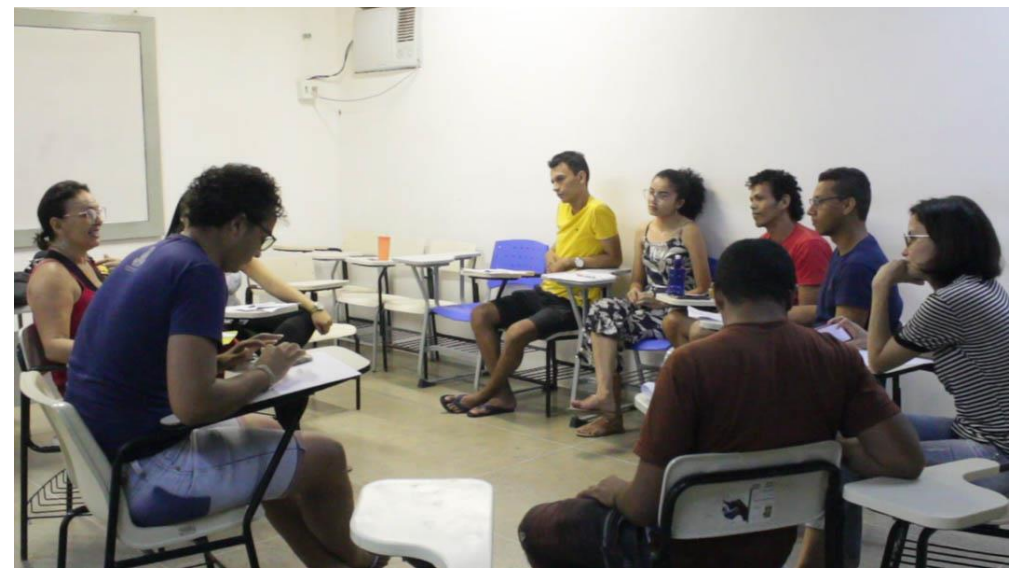

Foto: Autor (2019)

Etapa IV - Definição coletiva dos locais e datas das filmagens, figurino e produção necessária. As gravações também ocorreram nessa etapa. (figura 02)

Neste momento houve uma participação de todo o grupo (professoras e alunos/as), desenvolvendo as funções de atores e atrizes, maquiador, cinegrafista, direção, fotografia e técnico de som. Todo o processo foi realizado tentando produzir o material final com a máxima qualidade a partir dos recursos que se detinham, dessa forma foram tomados cuidados quanto a iluminação, figurinos e áudio, assim, nas etapas de finalização do vídeo, teriam menores detalhes a ser corrigidos.

Figura 02 - Preparação dos atores e Captura de imagens para o vídeo

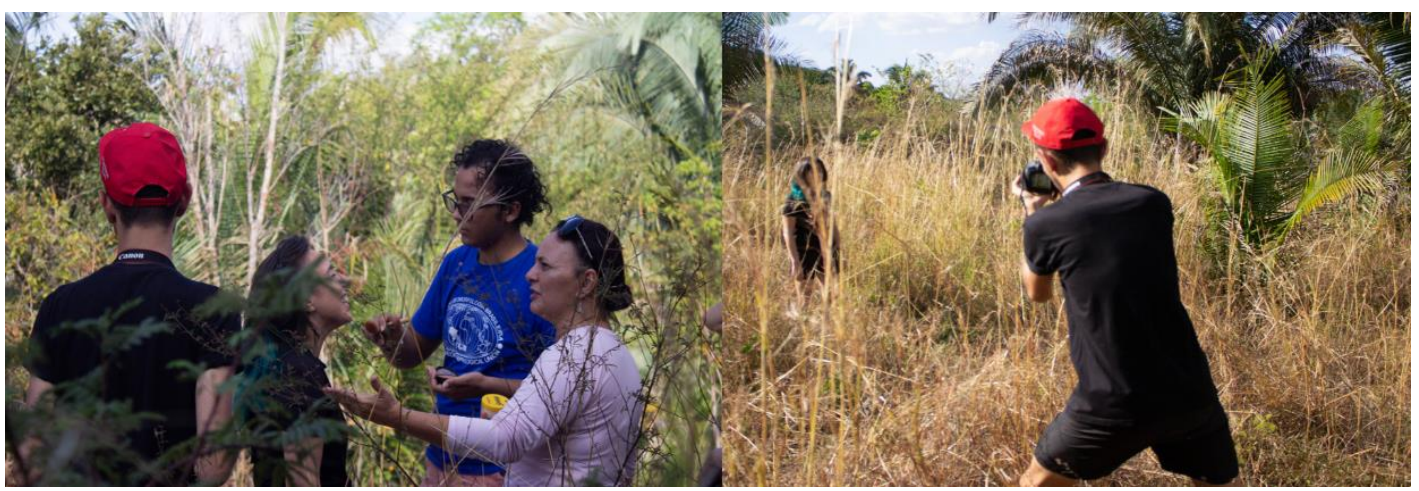

Fotos: Autor - 2019

Etapa $\mathrm{V}$ - Edição e montagem do vídeo e divulgação. A participação do grupo neste momento foi mais restrita, resumindo-se na participação da coordenadora do projeto, um bolsista, um professor e um profissional de edição.

Consistiu na seleção das melhores cenas capturadas ao longo dos encontros das filmagens, baseando-se na qualidade do conteúdo em relação ao conceito de paisagem como também qualidade das imagens conforme a proposta do vídeo.

Etapa VI - Avaliação, fase essencial da pesquisa ação, usada para conferir planos e ações, teoria e prática. Ocorreu através da exibição prévia do vídeo, restrita aos participantes do grupo com o intuito de avaliar dialogicamente se o resultado atingiu os objetivos propostos, para só então o material ser divulgado na plataforma digital.

Etapa VII - Divulgação nas plataformas virtuais. Ao final da edição do vídeo o material foi preparado para ampla divulgação. O vídeo foi convertido em dois formatos um para publicação na 
plataforma dos vídeos Youtube, onde se hospedou os vídeos produzidos pelo projeto Janela Geográfica, e o segundo formato foi para dispositivos móveis que poderia ser compartilhado em plataformas como WhatsApp,

O somatório das etapas resultou no vídeo educativo "Paisagem, expressão de vivência", disponível em: https://www.youtube.com/watch?v=ljExgVo21v4\&t=4s. O vídeo foi confeccionado na tessitura holística, buscando ressignificar interpretações conceituais pré-estabelecidas, optando por uma construção conjunta do conhecimento, trazendo uma releitura do conceito de paisagem dos grandes teóricos da Geografia, de forma artística e interconectada com a natureza.

\section{Resultados e discussão}

Os resultados desta experiência, no tocante aos aspectos teóricos, proporcionaram uma maior aproximação dos participantes com autores da Geografia humanista/cultural como Michel Collot (1990), Yi-Fu Tuan (1983), Carl Sauer (1998), dentre outros, mediada pelo estudo conceitual da categoria paisagem, que respaldou a proposta do vídeo como ferramenta didático-pedagógica do ensino da Geografia. A escolha desses teóricos deve-se a abordagem humanista sobre o estudo do ser humano, seus valores e experiências contribuindo para o projeto por considerarmos a experiência individual do aluno como elemento basilar.

Dessa forma, a Geografia humanista fundamenta a nossa proposta de ensino holístico da Geografia adotada tanto na produção do vídeo como na produção de conhecimento através dele, uma vez que apoiado em pressupostos como: subjetividade, intuição, sentimento, simbolismo, criatividade e a experiência como base de inteligibilidade do mundo, essa proposta possa ajudar a construir uma educação que coopera não só com a edificação do conhecimento dos alunos, mas também, e principalmente, na sua formação voltada para o desenvolvimento humano.

Vale ainda destacar, a vivência do trabalho interdisciplinar no processo de construção do vídeo e o contato com autores de outras áreas do conhecimento (artes, comunicação, linguagem áudio visual e educação) ampliaram e simultaneamente enriqueceram a formação docente dos educandos. Nesse sentido, cabe destacar a participação da professora Daniele Quiroga do curso de Artes Visuais da URCA, indicando textos e apresentando trabalhos de artistas plásticos como Valie Export que influenciou de sobremaneira a estética do vídeo, assim como as conversas realizadas com Rui Ferreira, profissional de edição de cinema e vídeo cultural.

Vinculada as premissas apresentadas, a Educomunicação teve um papel importante nessa experiência, haja vista que ela é um meio de fortalecimento do potencial comunicativo dos sujeitos e de seus grupos sociais, pois oportuniza outras vivências comunicacionais e educativas, diferenciadas das que são padrão nos espaços educativos e midiáticos da nossa sociedade. Podendo também ser considerada uma ação de intervenção e oposição ao que é hegemônico. (VIANA e XAVIER, 2015)

Durante a construção epistemológica da pesquisa, fomos surpreendidos(as) com as inúmeras conexões existentes entre educação holística, saber geográfico e educomunicação. As três comungam a fonte do protagonismo, da criatividade, criticidade, sensibilidade, interdisciplinaridade, dialogicidade e o compromisso de educar para o desenvolvimento humano, onde os sujeitos envolvidos no processo de ensino aprendizagem sejam capazes de assumir uma postura ativa e criativa na sociedade, indo além das paredes da sala de aula em busca de transformações sociais.

O vídeo "Paisagem, expressão de vivência", mais um dos resultados deste estudo, conseguiu aglutinar os aspectos materiais e imateriais existentes no espaço vivido de maneira artística e científica, reunindo linguagens distintas. O conceito de paisagem foi trabalhado através das definições de autores como Tuan (1983) e Sauer (1998) que versam sobre o assunto, sendo 
apresentado no vídeo por meio de imagens paisagísticas, mas também por meio da expressão corporal dos personagens que o interpretaram, dando literalmente "corpo" a afirmação de Collot (1990, p.27) de que "(...) a paisagem se define como espaço ao alcance do olhar, mas também à disposição do corpo; ela se reveste de significados ligados a todos os comportamentos possíveis do sujeito".

Os conceitos apresentados no vídeo foram escolhidos de maneira coletiva e apontam atributos sistêmicos, de totalidade, organicidade e subjetividade da paisagem, exemplificando diferentes abordagens ao conceito, com objetivo de complementar a discussão em sala de aula por diferentes pontos de vista. Assim a paisagem pode também ser representada em um modelo de atividade educativa fundamentada nos pressupostos da Geografia humanista e Educomunicação e dando "corpo" ao ensino holístico da Geografia.

A confecção do vídeo gerou entre os participantes discussões conceituais, estéticas e epistemológicas, assim como incitou reflexões sobre o fazer pedagógico, contribuindo substancialmente para um entendimento maior do processo de formação docente. Além de possibilitar o desenvolvimento de habilidades e competências referentes a linguagem audiovisual, abordando temas da Geografia de maneira provocadora do pensamento crítico em relação ao cotidiano do espaço vivido.

Todo esse movimento de discussão, reflexão e aprendizagem geradas no grupo, assim como o vídeo em si, só foi possível acontecer devido a comunicação. De acordo com Paulo Freire (1983), educação é comunicação e diálogo, é um encontro de sujeitos interlocutores que se expressão conjuntamente. De forma que na comunicação não há sujeitos passivos, pois há uma intencionalidade no conteúdo a ser comunicado.

Enfim, o projeto como um todo não só atingiu seu objetivo principal na produção de um material didático na linguagem do audiovisual feito por estudantes e professores, como proporcionou aos participantes novas perspectivas sobre a maneira de ensinar e aprender Geografia, adquirindo outros conhecimentos que estão além da própria formação.

\section{Considerações gerais}

A partir do projeto realizado, foi possível perceber que a Educomunicação amplia as possibilidades de democratização do conhecimento por utilizar as redes sociais, conseguindo atingir camadas da população muitas vezes excluídas pelo sistema educacional formal. A contemporaneidade das plataformas digitais interativas (Youtube, Instagram, Twiter, dentre outros) exercem nas pessoas um fascínio capaz de despertar o desejo de protagonizar seus processos de aprendizagem. Pois o sujeito ao interagir no ciberespaço trocando opiniões, informações, de maneira crítica, também produz conhecimento.

Quando um indivíduo se mostra conscientemente disposto a se envolver com uma atividade pedagógica, seja participar de um curso, um grupo de pesquisa ou produzir um vídeo, mantém interesse e atenção. Isso faz com que construa estratégias para superar os conflitos internos e externos que aparecem no percurso, portanto promove em si mesmo transformações inenarráveis.

Ressaltamos ainda que a produção do vídeo enriqueceu a formação acadêmica dos sujeitos envolvidos, ao possibilitar-lhes conhecer as etapas de realização de um produto audiovisual educativo de cunho geográfico, promovendo um diferencial na sua qualificação profissional como futuros professores e professoras de Geografia. A experiência demostra uma potencialidade em trabalhar com a educação holística o que torna o processo de construção mais rico e dinâmico para discente e docentes na construção do conteúdo através práticas integradoras. 
Em um contexto que as mídias estão cada vez mais presentes nas nossas vidas, o potencial dessas ferramentas para comunicar são oportunidades para a construção de espaços de ensino cada vez mais fluídos e com esse trabalho acreditamos está contribuindo para isso. O contexto de uma pandemia mundial ter se iniciado afetou drasticamente o cotidiano de muitos países e assim como em outros pilares importantes da sociedade, a educação ganhou um novo desafio frente ao distanciamento necessário atualmente.

A capacidade da educação de se reinventar de acordo com as mudanças na sociedade acompanham-na desde seu início, agora, mais uma vez, estamos atravessando um momento de reinvenção e os profissionais do ensino serão fundamentais para construir as bases da educação nesses novos modos. A Educomunicação surge para se atentar a esses tempos onde a circulação de informações em massa é infinita, e construir práticas educativas que acompanhem as transformações da educação e que proponham praticas integradoras e emancipatórias dos professores(as) e alunos(as) são cruciais, para continuarmos caminhando.

Portanto, Geografia e Educomunicação dialogam entre si, de modo que os docentes de Geografia estando atento às transformações do espaço e das sociedades, pode em conjunto com a Educomunicação reconhecer o papel que as mídias têm na sociedade e seus reflexos no ensino da própria Geografia e não só entender essas implicações, como também contribuir na divulgação e produção de materiais educativos. Dessa forma, poderemos ampliar os espaços que já se concretizam principalmente através da internet, podendo também chegar em outros meios de comunicação apresentando ideias recentes como a abordagem holística no ensino de Geografia. 


\section{Referências}

BALDISSERA, A. (2020) Pesquisa-Ação: uma Metodologia do "Conhecer" e do "Agir" Coletivo. Sociedade em Debate, Pelotas, v. 7, n. 2, p. 5-25. Disponível em: <http://revistas.ucpel.edu.br/index.php/rsd/article/viewFile/570/510>. Acessado em: 04 jan. 2020. BARBOSA, J. L. (2008) Geografia e Cinema: em busca de aprovações e do inesperado. In: CARLOS, A. F. A. (Org.). A Geografia em sala de aula. 8 ed. São Paulo: Contexto. p.109-133 BRASIL. (1998) Parâmetros Curriculares Nacionais: Geografia. Brasília: MEC/SEF. 156 p. Disponível em: < http://portal.mec.gov.br/seb/arquivos/pdf/geografia.pdf>. Acessado em: 18/06/2020 BRASIL. (2018) Base Nacional Comum Curricular. Brasília: Ministério de Educação e Cultura. 600 p. Disponível em: < http://basenacionalcomum.mec.gov.br/images/BNCC EIEF110518versaofinalsite.pdf>. Acessado em: 18/06/2020

CASTELLAR, S. M. V. (2005) Educação geográfica: a psicogenética e o conhecimento escolar. Cadernos Cedes, Campinas. V. 25, n.66, p. 209-225. Disponível em: < http://www.cedes.unicamp.br>. Acessado em 08.fev.2021.

COLLOT, M. (1990) Pontos de vista sobre a percepção das paisagens. Boletim de Geografia Teorética, v. 20, n. 39, p. 21-32.

CORTES, T. P. B. B.; MARTINS, A. O.; SOUZA, C. H. M. (2018) Educação midiática, educomunicação e formação docente: parâmetros dos últimos 20 anos de pesquisas nas bases Scielo e Scopus. Educação em Revista, Belo Horizonte, v. 34, p. 1-39. Disponível em: < https://doi.org/10.1590/0102-4698200391 >. Acessado em 18. fev. 2020.

FREIRE, P. (1983) Extensão ou Comunicação?. $7^{\circ}$ ed. Rio de Janeiro: Paz e Terra. 93 p.

FREIRE, P. (2020) Educação e Mudança. 41ª ed. Rio de Janeiro: Paz e Terra. 112 p.

HASLINGER E. O.; SAGGIN, L.; ALBUQUERQUE, M. Z. (2017) A interface da educação e comunicação para além dos muros da escola: educomunicação como práxis libertadoras no contexto não escolar. In: SOARES, I. O.; VIANA, C. E.; XAVIER, J. B. (Org.). Educomunicação e suas áreas de intervenção: novos paradigmas para o diálogo intercultural. São Paulo: ABPEducom, p. 89-94.

MATURANA, H. R. (2005). Emoções e linguagem na educação e na política. $4^{a}$ reimpressão. Belo Horizonte: Ed. UFMG. 98 p.

MENEZES, L. (2017) O vídeo nos processos de ensino aprendizagem. Curso de Produção de Vídeo. PACC, UAB, UFABC. Disponível em: <http://proec.ufabc.edu.br/uab/prodvideo /TEXTO\%204\%20VIDEO\%20E\%20 ENSINO.pdf>. Acessado em: 13 dez 2019.

OLIVA, J. T. (2008) Ensino de Geografia: um retrato desnecessário. In: CARLOS, A. F. A. (Org.). A Geografia em sala de aula. 8 ed., $2^{\text {a }}$ reimpressão - São Paulo: Contexto. p.34-49

OLIVEIRA JUNIOR, W. M.; GIRARDI, G. (2011) Diferentes linguagens no ensino de geografia. In: Anais do XI Encontro Nacional de Prática de Ensino de Geografia. Goiânia. XI ENPEG, Goiânia, v. 1, p. 1-9.

ORTIZ, F. C. (2017) A Educomunicação, caminho inovador para transcender Barreiras Culturais à Comunicação: experiências brasileiras e cubanas. In: SOARES, I. O.; VIANA, C. E.; XAVIER, J. B. (Orgs.). Educomunicação e suas áreas de intervenção: novos paradigmas para o diálogo intercultural. São Paulo: ABPEducom. p. $174-185$.

PAZZINI, D. N. A.; ARAUJO, F. V. (2013) O uso do vídeo como ferramenta de apoio ao ensinoaprendizagem. Curso de Mídias na Educação, Santa Maria, UFSM. Disponível em:<https://repositorio.ufsm.br/bitstream/handle/1/729/Pazzini_Darlin_Nalu_Avila.pdf?sequence=1 \&isAllowed $=y>$. Acessado em: 25 set. 2019.

PRÓSPERO, D. (2017) A Educação Integral na perspectiva da Educomunicação: a implementação no Programa São Paulo Integral. In: SOARES, I. O.; VIANA, C. E.; XAVIER, J. B.; (Orgs.). Educomunicação e 
suas áreas de intervenção: novos paradigmas para o diálogo intercultural. São Paulo: ABPEducom. p. $65-71$.

RADDATZ, V. L. S. (2015) Relações entre Educomunicação e Direitos Humanos no ponto de vista de Ismar de Oliveira Soares. In: LAGO, C.; VIANA, C. E. (orgs.) Educomunicação: caminhos da sociedade midiática pelos direitos humanos. São Paulo: ABPEducom, p. 29-36.

RODRIGUES, G.; MANAIA, C. (2017) A cultura das mídias e os processos de aprendizagem no ensino de Geografia. In: SOARES, I. O.; VIANA, C. E.; XAVIER, J. B. (Org.). Educomunicação e suas áreas de intervenção: novos paradigmas para o diálogo intercultural. São Paulo: ABPEducom, p. 739 - 744 SAUER, C. O. (1998) A morfologia da paisagem. In: CORREAA, R. L.; ROSENDAHL, Z. (orgs.). Paisagem, tempo e cultura. Rio de Janeiro: EdUERJ, p. 12-74.

SELBACH, S. (2010) Geografia e Didática. Rio de Janeiro: Vozes. 149p

SOARES, I. O. (2000) Educomunicação: um campo de mediações. Comunicação \& Educação, São Paulo, n. 9, p. 12-24. Disponivel em: http://www.revistas.usp.br/ comueduc/article/view/36934/39656. Acessado em: 15.set. 2020.

TUAN, Y. (1983) Espaço e lugar: a perspectiva da experiência. São Paulo: Difel. 248 p.

VIANA, C. E.; XAVIER, J. B. (2015) Direitos humanos e comunicação: um tema gerador de debates e encontros sob a perspectiva da educomunicação. In. In: LAGO, C.; VIANA, C. E. (orgs.) Educomunicação: caminhos da sociedade midiática pelos direitos humanos. São Paulo: ABPEducom, p. $16-24$

YUS, R. (2002) Educação Integral: uma educação holística para o século XXI. Trad. Daisy Vaz de Moraes. Porto Alegre: Artmed, $270 \mathrm{p}$. 